\title{
Health effects of environmental pollution in population living near industrial complex areas in Korea
}

\author{
Sang-Yong Eom', Jonghyuk Choi², Sanghyuk Bae², Ji-Ae Lim², Guen-Bae Kim³, Seung-Do Yu³, Yangho Kim ${ }^{4}$, \\ Hyun-Sul Lim ${ }^{5}$, Bu-Soon Son ${ }^{6}$, Domyung Paek , Yong-Dae Kim', Heon Kim', Mina Ha², Ho-Jang Kwon² \\ 'Department of Preventive Medicine, Chungbuk National University College of Medicine, Cheongju, Korea; ${ }^{2}$ Department of Preventive Medicine, \\ Dankook University College of Medicine, Cheonan, Korea; ${ }^{3}$ Environmental Health Research Division, Environmental Health Research Department, \\ National Institute of Environmental Research, Incheon, Korea; ${ }^{4}$ Department of Occupational and Environmental Medicine, Ulsan University Hospital, \\ University of Ulsan College of Medicine, Ulsan, Korea; ${ }^{5}$ Department of Preventive Medicine, Dongguk University College of Medicine, Gyeongju, Korea; \\ ${ }^{6}$ Department of Environmental Health Science, Soonchunhyang University, Asan, Korea; ${ }^{7}$ Graduate School of Public Health, Seoul National University, \\ Seoul, Korea
}

Several epidemiological studies have reported an association between environmental pollution and various health conditions in individuals residing in industrial complexes. To evaluate the effects of pollution from industrial complex on human health, we performed a pooled analysis of environmental epidemiologic monitoring data for residents living near national industrial complexes in Korea. The respiratory and allergic symptoms and the prevalence of acute and chronic diseases, including cancer, were used as the outcome variables for health effects. Multiple logistic regression analysis was used to analyze the relationship between exposure to pollution from industrial complexes and health conditions. After adjusting for age, sex, smoking status, occupational exposure, level of education, and body mass index, the residents near the industrial complexes were found to have more respiratory symptoms, such as cough (odds ratio [OR], 1.18; 95\% confidence interval [Cl], 1.06 to 1.31) and sputum production $(\mathrm{OR}, 1.13 ; 95 \% \mathrm{Cl}, 1.03$ to 1.24$)$, and symptoms of atopic dermatitis $(\mathrm{OR}, 1.10 ; 95 \% \mathrm{Cl}, 1.01$ to 1.20). Among residents of the industrial complexes, the prevalence of acute eye disorders was approximately $40 \%$ higher $(\mathrm{OR}, 1.39 ; 95 \% \mathrm{Cl}, 1.04$ to 1.84$)$ and the prevalence of lung and uterine cancer was 3.45 times and 1.88 times higher, respectively, than those among residents of the control area. This study showed that residents living in the vicinity of industrial complexes have a high risk of acute and chronic diseases including respiratory and allergic conditions. These results can be used as basic objective data for developing health management measures for individuals residing near industrial complexes.

Keywords: Health effect, Respiratory disease, Allergic disease, Industrial complex, Prevalence, Symptom

\section{INTRODUCTION}

Ambient air pollution is a confirmed human carcinogen (International Agency for Research on Cancer Group 1) [1], and the World Health Organization estimates that approximately 7 million people worldwide die annually from air pollution [2]. The number of premature deaths from air pollution is expected to double by 2050 [3], and the burden of diseases caused by air pollution is expected to continuously increase.

Air pollution is caused by industrial activities and the burning

Received: September 1, 2017 Accepted: January 15, 2018

Corresponding author: Ho-Jang Kwon

Department of Preventive Medicine, Dankook University College of Medicine,

119 Dandae-ro, Dongnam-gu, Cheonan 31116, Korea

E-mail: hojang@dankook.ac.kr

This article is available from: http://e-eht.org/ of fossil fuels and waste. Complexes with large-scale industrial activities are stationary sources of various environmental pollutants, such as fine dust, sulfur dioxide $\left(\mathrm{SO}_{2}\right)$, nitrogen dioxide $\left(\mathrm{NO}_{2}\right)$, carbon monoxide $(\mathrm{CO})$, ozone $\left(\mathrm{O}_{3}\right)$, volatile organic compounds (VOC), polycyclic aromatic hydrocarbons (PAH), and heavy metals [4]. The pollutants emitted from industrial complexes enter human body through the respiratory system or skin and can cause allergic reactions, respiratory symptoms, and various acute and chronic diseases, such as asthma, chronic obstructive pulmonary diseases, lung dysfunctions, skin and eye diseases, acute bronchitis, cardiovascular disease, and cancer [4-10].

To date, many epidemiological studies have been conducted to evaluate the effect of exposure to air pollution from industrial complexes on health [4]. However, most conducted studies were of ecological design using cancer registry data or 
mortality data, and the control of confounding variables was limited. In addition, large-scale epidemiological studies with sufficient statistical power are lacking. To systematically investigate the health effects of industrial complexes on local residents, the National Institute of Environmental Research (NIER) of Korea initiated the project "Monitoring of Exposure to Environmental Pollutants and Health Effects among Residents Living near Industrial Complex" in 2003. After the comprehensive evaluation of the first phase of the project in 2011, the second phase started in 2012 and lasted until 2015 and was designed as an environmental epidemiologic monitoring conducted as cross-sectional studies in the 5 regions of Ulsan, Sihwa/Banwol, Pohang, Gwangyang Bay, and Cheongju/Daesan. This study was carried out to comprehensively evaluate the health effects of industrial complexes using data from the environmental epidemiological surveillance survey of the national industrial complexes in Korea from 2012 to 2015.

\section{METHODS}

\section{Study Sulbjects and Data}

The subjects of this study were 35530 adults aged 20 years and older participating in the second phase of the Monitoring of Exposure to Environmental Pollutants and Health Effects among Residents Living near Industrial Complex project in the 5 regions of Ulsan, Sihwa/Banwol, Pohang, Gwangyang Bay, and Cheongju/Daesan from 2012 to 2015. The study subjects comprised 26689 adults who were residents of areas near industrial complexes and 8841 individuals residing in the control areas. The vicinities of industrial complexes were defined as nearby residential areas expected to be exposed to pollutant emissions from industrial complexes. The control areas were defined as the regions outside the influence of industrial complexes. The study areas were selected based on the distribution of wind direction, geographical characteristics, and the results of an air pollution diffusion modelling. All data were obtained from the NIER of Korea and refined based on standard coding guidelines. The integrated database was then constructed. The database included demographic characteristics, lifestyle habits, disease history, environmental and occupational exposures, dietary habits, time-activity pattern, and respiratory and allergic symptoms. Smokers were defined as individuals who had smoked more than 20 packs of cigarettes during their lifetime. Non-drinkers were defined as those who reject alcohol due to religious reasons or were not drinking alcohol. Occupational exposure to harmful substances was defined as exposure to dust (sawdust, road, glass fiber, silica, and mine dust), fume (welding fume, soldering and flux fume, plastic fume, paint fume, gasoline, and diesel fuel fumes), and chemical substances (organic solvents, bonds, or resins).

\section{Definition of Respiratory and Allergic Symptoms and Acute and Chronic Diseases}

This study used symptoms of respiratory and allergic diseases as well as diagnoses of acute or chronic disease as outcome variables to evaluate the effects of the industrial complexes on health. The symptoms of respiratory disease were divided into cough, sputum production, dyspnea, and wheezing. The symptoms of cough and sputum production were defined as having responded positively to "dry cough in the mornings after waking or coughing often while awake during the day" and "experiencing dry sputum in the mornings after waking or spitting or swallowing sputum while awake during the day," respectively. Dyspnea and wheezing symptoms were defined as responding positively to "having experience of feeling closed in and difficulties in breathing" and "experiencing wheezing sounds, whistling, or cat noises in the chest," respectively. The symptoms of allergic disease were classified into rhinitis, dermatitis, and conjunctivitis. Individuals experiencing sneezing or congestion without a cold or flu was defined as having allergic rhinitis, and those experiencing a minimum of 6 months of intermittent pruritus was defined as having atopic dermatitis. When respondents experienced ocular pruritus without conjunctivitis, they were considered to have allergic conjunctivitis. The prevalence of acute or chronic diseases was defined as the proportion of people diagnosed of the disease by a physician and included all individuals who were either diagnosed, under treatment, or fully cured.

\section{Statistical Analysis}

The differences in age, sex, body mass index (BMI), level of education, smoking status, drinking status, duration of residence, and occupational history between those in the industrial and control areas were tested using the student's $t$-test or chi-square test. Multiple logistic regression analysis was conducted to determine whether the risk of the symptoms of respiratory and allergic diseases and prevalence of chronic and acute diseases in the industrial area was higher than those in the control area. Potential confounding variables such as age, sex, BMI, level of education, occupational exposure to hazardous materials, and smoking status were selected based on the results of univariate analysis and previous studies [11-14] and were included in multiple logistic models as covariates. In addition, the key confounding variables of age (below 50 or above 50), smoking status (present or past smoker, non-smoker), and occupational exposure were subjected to stratified 
analyses. Breslow-Day test was conducted to evaluate the homogeneity of each stratum. To evaluate the temporal change in the symptoms of respiratory and allergic disease and the prevalence of acute and chronic diseases, stratified analysis was performed according to the survey period. All statistical analyses were conducted using SPSS version 23.0 (IBM Corp., Armonk, NY, USA).

\section{RESULTS}

The average age of the subjects living in the industrial and control area was $51.9 \pm 16.4$ years and $52.6 \pm 16.1$ years, respectively. Elderly over the age of 60 years were more distributed in the control area than in the industrial area. The subjects were equally distributed between 2012 and 2014. Although no differences in sex, BMI, level of education, and duration of residence were observed, the rates of smoking and drinking were higher among residents of the control area than that among residents of the industrial area. The occupational exposure to hazardous materials was significantly higher in the industrial area than that in the control area (Table 1).

The number of residents with symptoms of cough and sputum production was higher in the industrial area than in the control area. After adjusting for potential confounding vari- ables, the risk of having cough and sputum was significantly higher for residents of the industrial area (odds ratio [OR] and 95\% confidence interval [CI] for cough, 1.18; 95 CI, 1.06 to 1.31; for sputum, 1.13; 95\% CI, 1.03 to 1.24 ). However, a statistically insignificant positive relationship was noted between dyspnea and wheezing. Among the symptoms of allergic disease, atopic dermatitis was significantly higher in the industrial area (OR, 1.10; 95\% CI, 1.01 to 1.20) and the risk of allergic rhinitis was approximately $5 \%$ higher, with marginal significance, than in the control area (OR, 1.05; 95\% CI, 0.99 to 1.12) (Table 2).

Table 3 presents the prevalence rates of chronic and acute diseases in the industrial and control areas. The prevalence of acute eyes disorder was significantly different between the two groups. After adjusting for potential confounding variables, the relationship was still statistically significant (OR, 1.39; 95\% CI, 1.04 to 1.84). The prevalence of the risk of acute bronchitis was approximately $26 \%$ higher in residents of industrial areas, but these results were not statistically significant ( $p=0.13)$. The prevalence of asthma was $2.1 \%$ for the industrial area and $1.8 \%$ for the control area. The prevalence of the risks of lung and uterine cancers in the industrial area was statistically significantly higher at 3.45 and 1.88 times, respectively.

Table 4 shows the stratification results for cough, sputum, allergic dermatitis, acute eye disorder, lung cancer, and uterine

Table 1. General characteristics of the study subjects

\begin{tabular}{|c|c|c|c|}
\hline Characteristics & Industrial area & Control area & $p$-value \\
\hline Total (n) & 26689 & 8841 & \\
\hline Age (y) & $51.9 \pm 16.4$ & $52.6 \pm 16.1$ & $<0.001$ \\
\hline Age $(\%)$ & & & $<0.001$ \\
\hline$<29$ & 11.2 & 9.3 & \\
\hline $30-39$ & 13.2 & 13.0 & \\
\hline $40-49$ & 19.3 & 20.7 & \\
\hline $50-59$ & 21.8 & 20.7 & \\
\hline $60-69$ & 17.8 & 19.0 & \\
\hline$\geq 70$ & 16.7 & 17.4 & \\
\hline Year of recruitment (n) & & & 0.63 \\
\hline 2012 & 6137 & 2092 & \\
\hline 2013 & 6741 & 2204 & \\
\hline 2014 & 6984 & 2292 & \\
\hline 2015 & 6827 & 2253 & \\
\hline Regions (n) & & & $<0.001$ \\
\hline Ulsan & 3507 & 1131 & \\
\hline Shiwha/Banweol & 6459 & 1881 & \\
\hline Gwangyang Bay & 8461 & 2989 & \\
\hline Cheongju & 4071 & 1466 & \\
\hline Daesan & 726 & 240 & \\
\hline Pohang & 3468 & 1134 & \\
\hline Sex, males (\%) & 45.6 & 45.9 & 0.60 \\
\hline Body mass index $\left(\mathrm{kg} / \mathrm{m}^{2}\right)$ & $23.4 \pm 2.9$ & $23.4 \pm 2.8$ & 0.17 \\
\hline Education, < high school (\%) & 36.1 & 36.4 & 0.61 \\
\hline Smokers (current- or ex-smokers) (\%) & 26.9 & 28.1 & $<0.001$ \\
\hline Drinkers (\%) & 54.3 & 55.7 & 0.02 \\
\hline Duration of residence in current address (y) & $15.0 \pm 12.1$ & $15.2 \pm 12.1$ & 0.18 \\
\hline Occupational exposure, yes (\%) & 28.0 & 25.8 & $<0.001$ \\
\hline
\end{tabular}


Table 2. Comparison of prevalence of self-reported symptoms for respiratory and allergic diseases

\begin{tabular}{|c|c|c|c|c|}
\hline Symptoms & Industrial area & Control area & $\mathrm{OR}(95 \% \mathrm{Cl})^{\mathrm{a}}$ & $p$-value \\
\hline \multicolumn{5}{|l|}{ Respiratory } \\
\hline Cough & $1772(6.6)$ & $500(5.7)$ & $1.18(1.06,1.31)$ & 0.002 \\
\hline Sputum & 2194 (8.2) & $645(7.3)$ & $1.13(1.03,1.24)$ & 0.008 \\
\hline Dyspnea & $2114(7.9)$ & $629(7.1)$ & $1.08(0.98,1.18)$ & 0.12 \\
\hline Wheezing & $818(3.1)$ & $250(2.8)$ & $1.06(0.92,1.23)$ & 0.42 \\
\hline Allergic rhinitis & $5451(20.5)$ & $1710(19.4)$ & $1.05(0.99,1.12)$ & 0.09 \\
\hline Atopic dermatitis & $2435(9.2)$ & $739(8.4)$ & $1.10(1.01,1.20)$ & 0.03 \\
\hline Allergic conjunctivitis & $4462(16.8)$ & $1424(16.1)$ & $1.04(0.97,1.11)$ & 0.25 \\
\hline
\end{tabular}

Values are presented as number (\%).

$\mathrm{OR}$, odds ratio; $\mathrm{Cl}$, confidence interval.

${ }^{a}$ Adjusted for age, sex, body mass index, smoking, education level, and occupational exposure.

Table 3. Comparison of prevalence of doctor-diagnosed acute and chronic diseases

\begin{tabular}{|c|c|c|c|c|}
\hline Diseases & Industrial area & Control area & OR $(95 \% \mathrm{Cl})^{\mathrm{a}}$ & $p$-value \\
\hline Acute bronchitis & $203(0.8)$ & $55(0.6)$ & $1.26(0.93,1.70)$ & 0.13 \\
\hline Pneumonia & $161(0.6)$ & $66(0.8)$ & $0.78(0.59,1.04)$ & 0.09 \\
\hline Acute eyes disorder & $250(0.9)$ & $60(0.7)$ & $1.39(1.04,1.84)$ & 0.02 \\
\hline Acute dermatic disorder & $168(0.6)$ & $48(0.6)$ & $1.14(0.83,1.58)$ & 0.42 \\
\hline Chronic obstructive pulmonary disease & $271(1.0)$ & $90(1.0)$ & $1.00(0.79,1.28)$ & 0.98 \\
\hline Asthma & $548(2.1)$ & $156(1.8)$ & $1.17(0.98,1.41)$ & 0.08 \\
\hline Sinusitis & $593(2.2)$ & $200(2.3)$ & $0.96(0.82,1.13)$ & 0.66 \\
\hline Allergic rhinitis & $2169(8.2)$ & $729(8.3)$ & $0.96(0.88,1.05)$ & 0.34 \\
\hline Allergic dermatitis & $718(2.7)$ & $233(2.7)$ & $1.00(0.86,1.17)$ & 0.96 \\
\hline Allergic conjunctivitis & $380(1.4)$ & $134(1.5)$ & $0.91(0.75,1.11)$ & 0.37 \\
\hline Hypertension & $5356(20.1)$ & $1839(20.9)$ & $0.99(0.93,1.06)$ & 0.78 \\
\hline Stroke & $464(1.8)$ & $136(1.5)$ & $1.18(0.97,1.43)$ & 0.10 \\
\hline Anginae/myocardial infarction & $558(2.1)$ & $191(2.2)$ & $1.01(0.86,1.20)$ & 0.87 \\
\hline Diabetes & $2366(8.9)$ & $826(9.4)$ & $0.99(0.91,1.08)$ & 0.81 \\
\hline Anemia & $910(3.4)$ & $301(3.4)$ & $1.02(0.89,1.17)$ & 0.73 \\
\hline Thyroid disease & $820(3.1)$ & 299 (3.4) & $0.90(0.79,1.03)$ & 0.13 \\
\hline Lung cancer & $40(0.2)$ & $4(0.1)$ & $3.45(1.23,9.66)$ & 0.02 \\
\hline Stomach cancer & $149(0.6)$ & $44(0.5)$ & $1.03(0.73,1.45)$ & 0.86 \\
\hline Colon cancer & $88(0.3)$ & $24(0.3)$ & $1.21(0.77,1.91)$ & 0.40 \\
\hline Liver cancer & $26(0.1)$ & $8(0.1)$ & $1.04(0.47,2.30)$ & 0.92 \\
\hline Breast cancer, female & $78(0.5)$ & $28(0.6)$ & $0.91(0.59,1.41)$ & 0.68 \\
\hline Uterine cancer, female & $75(0.5)$ & $13(0.3)$ & $1.88(1.04,3.40)$ & 0.04 \\
\hline
\end{tabular}

Values are presented as number (\%).

$\mathrm{OR}$, odds ratio; $\mathrm{Cl}$, confidence interval.

${ }^{a}$ Adjusted for age, sex, body mass index, smoking, education level, and occupational exposure.

Table 4. Odds ratio and 95\% confidence interval of selected health events according to age, smoking status, and occupational exposure

\begin{tabular}{|c|c|c|c|c|c|c|c|c|c|}
\hline \multirow{2}{*}{ Symptoms } & \multicolumn{2}{|c|}{ Age (y) } & \multirow{2}{*}{$p$-homogeneity } & \multicolumn{2}{|c|}{ Smoking status } & \multirow{2}{*}{$p$-homogeneity } & \multicolumn{2}{|c|}{ Occupational exposure } & \multirow{2}{*}{$p$-homogeneity } \\
\hline & $<50$ & $\geq 50$ & & Non-smokers & Ex-smokers & & No & Yes & \\
\hline \multicolumn{10}{|l|}{ Respiratory } \\
\hline Cough & $\begin{array}{c}1.18 \\
(1.05,1.34)\end{array}$ & $\begin{array}{c}1.17 \\
(0.97,1.41)\end{array}$ & 0.82 & $\begin{array}{c}1.11 \\
(0.97,1.26)\end{array}$ & $\begin{array}{c}1.31 \\
(1.10,1.55)\end{array}$ & 0.19 & $\begin{array}{c}1.23 \\
(1.08,1.41)\end{array}$ & $\begin{array}{c}1.11 \\
(0.94,1.31)\end{array}$ & 0.27 \\
\hline Sputum & $\begin{array}{c}1.14 \\
(1.02,1.27)\end{array}$ & $\begin{array}{c}1.12 \\
(0.94,1.33)\end{array}$ & 0.72 & $\begin{array}{c}1.15 \\
(1.02,1.30)\end{array}$ & $\begin{array}{c}1.11 \\
(0.97,1.28)\end{array}$ & 0.75 & $\begin{array}{c}1.23 \\
(1.09,1.40)\end{array}$ & $\begin{array}{c}1.01 \\
(0.88,1.17)\end{array}$ & 0.03 \\
\hline Atopic dermatitis & $\begin{array}{c}1.12 \\
(1.02,1.24)\end{array}$ & $\begin{array}{c}1.03 \\
(0.86,1.23)\end{array}$ & 0.56 & $\begin{array}{c}1.12 \\
(1.01,1.24)\end{array}$ & $\begin{array}{c}1.05 \\
(0.89,1.23)\end{array}$ & 0.51 & $\begin{array}{c}1.10 \\
(0.99,1.21)\end{array}$ & $\begin{array}{c}1.11 \\
(0.94,1.31) t\end{array}$ & 0.95 \\
\hline Acute eyes disorder & $\begin{array}{c}1.26 \\
(0.87,1.82)\end{array}$ & $\begin{array}{c}1.63 \\
(1.03,2.57)\end{array}$ & 0.47 & $\begin{array}{c}1.40 \\
(1.01,1.94)\end{array}$ & $\begin{array}{c}1.35 \\
(0.76,2.40)\end{array}$ & 0.97 & $\begin{array}{c}1.34 \\
(0.95,1.87)\end{array}$ & $\begin{array}{c}1.56 \\
(0.91,2.67)\end{array}$ & 0.61 \\
\hline Lung cancer & $\begin{array}{c}2.67 \\
(0.61,11.63)\end{array}$ & $\begin{array}{c}4.23 \\
(1.00,17.99)\end{array}$ & 0.64 & $\begin{array}{c}4.00 \\
(0.95,16.95)\end{array}$ & $\begin{array}{c}2.89 \\
(0.66,12.63)\end{array}$ & 0.74 & $\begin{array}{c}3.41 \\
(1.04,11.23)\end{array}$ & $\begin{array}{c}3.31 \\
(0.43,25.59)\end{array}$ & 0.91 \\
\hline Uterine cancer, female & $\begin{array}{c}1.77 \\
(0.83,3.76)\end{array}$ & $\begin{array}{c}2.03 \\
(0.79,5.24)\end{array}$ & 0.82 & $\begin{array}{c}1.94 \\
(1.05,3.57)\end{array}$ & $\begin{array}{c}0.81 \\
(0.08,8.59)\end{array}$ & 0.67 & $\begin{array}{c}2.17 \\
(0.98,4.83)\end{array}$ & $\begin{array}{c}1.52 \\
(0.63,3.67)\end{array}$ & 0.59 \\
\hline
\end{tabular}




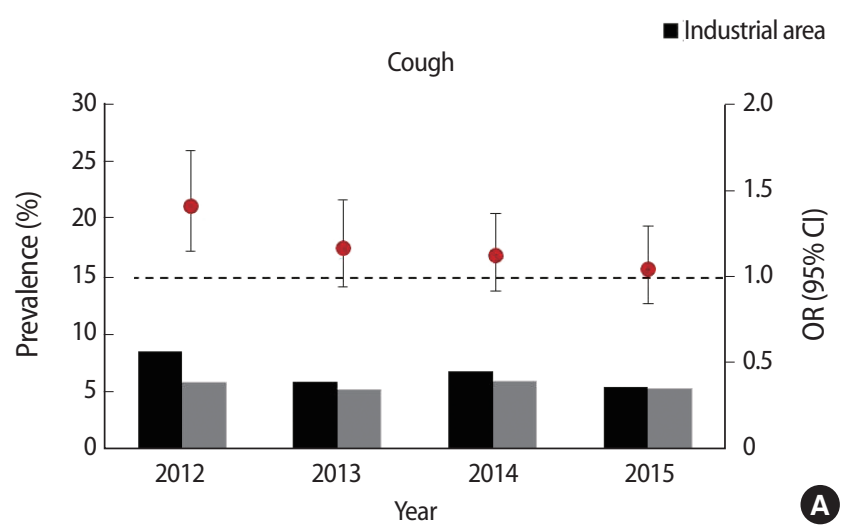

m Control area
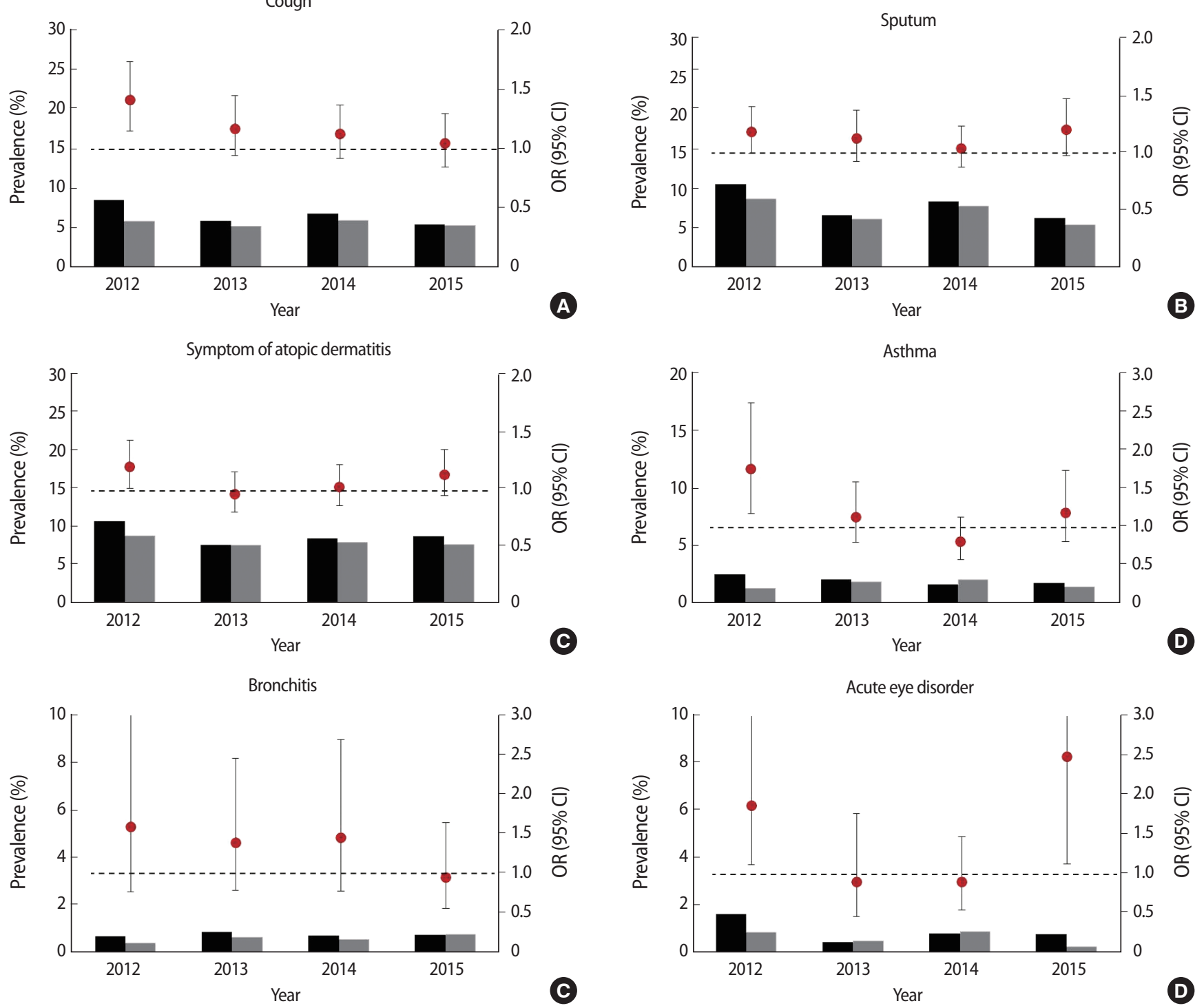

Figure 1. Temporal change of self-reported symptoms for respiratory and allergic diseases (A, B, and C) and doctor-diagnosed diseases (D, E, and F), Environmental Health Survey in the vicinity of national industrial complex, 2012-2015, Korea. OR, odds ratio; Cl, confidence interval.

cancer according to potential confounding variables such as age, smoking, and occupational exposure. The homogeneity of the prevalence risk was confirmed for the potential confounding variables with respect to sputum production, except for the occupational exposure. The risk of sputum production differed significantly according to occupational exposure (non-occupational exposure group: OR, 1.23; 95\% CI, 1.09 to 1.40; occupational exposure group: OR, 1.01; $95 \% \mathrm{CI}, 0.88$ to 1.17; $p$ for homogeneity=0.03).

Figure 1 shows the temporal changes of the health outcomes between 2012 and 2015. The trend of cough has been evidently decreasing since 2012. However, sputum production and atopic dermatitis had a U-shaped trend. The overall prevalence of acute bronchitis decreased, while that of asthma and acute eye disorder initially decreased followed by an increase in 2015 .

\section{DISCUSSION}

We compared the symptoms of respiratory and allergic disease and the prevalence rates of acute and chronic diseases between the residents of areas in the vicinity of Korean industrial complexes and those in the control regions using integrated data for environmental epidemiology monitoring from 2012 to 2015 . We found that the residents living near the industrial complexes experienced more respiratory and atopic symptoms such as cough and sputum production, and the 
risk of acute eye disorder and lung and uterine cancers is higher in industrial areas than that in the control areas.

This study revealed that residents of industrial complexes experienced more respiratory symptoms such as cough and sputum production than those in control areas. Air pollutants are known to lead to irritation and infections of the respiratory tract [15]. Coughing is the body's defense mechanism to remove contaminants from the lungs and bronchi when the pollutants enter through the respiratory tract. Sputum production indicates increased airway secretion or inflammatory response of the lungs due to exposure to contaminants [16]. Therefore, the increase in the incidence of cough and sputum symptoms indicates that residents in industrial areas are more exposed to air pollutants than those in the control area. Similar to our results, previous epidemiological studies have also shown that residing near industrial complexes increased the exposure to air pollutants and the incidence of cough and sputum symptoms [17-19]. In this study, although a statistical significance was not observed, the prevalence of respiratory diseases such as dyspnea, wheezing and bronchitis, chronic obstructive pulmonary disease, and asthma was also higher in the industrial area than in the control area.

The incidence of atopic dermatitis was also statistically higher in the industrial area than in the control area. Similar to our results, previous epidemiological studies reported the association of exposure to various air pollutants such as $\mathrm{CO}, \mathrm{NO}_{2}$, and fine dusts and to symptoms and exacerbation of atopic dermatitis $[20,21]$. Although the specific mechanism is yet to be determined, the development of atopic dermatitis symptoms due to air pollutants can be attributed to the induction of inflammation by an abnormal immune response associated with increased serum IgE and increased Th2 cytokine expression [15,22]. In addition, the risk of acute eye disorder in the industrial area was approximately $40 \%$ higher than that in the control area. Previous studies have reported that exposure to air pollutants such as $\mathrm{SO}_{2}$ and $\mathrm{O}_{3}$ on the ocular surface was associated with eye diseases such as conjunctivitis and dry eye syndrome [10,23,24].

Currently, numerous epidemiological studies on the relationship between exposure to pollutants from industrial complexes and cancer or mortality have been conducted $[1,4,25$ 30]. While the exact carcinogenic mechanism is still unclear, most air pollutants are absorbed into the body, acting as a source of oxidative stress by reactive oxygen species. Oxidative stress damages the proteins, lipids, cellular membranes, and DNA, resulting in genomic instability that causes mutations of normal cells into malignant cells [31-33].

In the present study, the risk of lung cancer was significantly higher among residents living in industrial complexes than that in the control area even after adjusting for age, sex, smoking, occupational exposure, education, and BMI. Similarly, Belli et al. [25] found that the incidence of lung cancer increased by approximately three times among residents living within $2 \mathrm{~km}$ of a petrochemical plant, and many epidemiological studies have also reported a significant association between residence near industrial parks and lung cancer incidence [2629]. In addition, our study observed a higher risk of uterine cancer among female residents of industrial areas than those in the control area. However, no correlations between air pollution or residing near industrial complexes and the risk of uterine cancer have been reported. The Nurses' Health Study found a significant relationship between chronic exposure to particulate matter and the occurrence of uterine leiomyomata, a benign tumor in the uterus [34]. Umezawa et al. [35] have identified a relationship between exposure to diesel exhaust particulates and endometriosis in an animal study. Although the etiology of uterine cancer is unclear, it is known to be related to disorders of hormone secretion such as estrogen as well as metabolic disorders such as insulin resistance [36,37], and various air pollutants can disrupt endocrine function [38,39].

The emission pollutants in the industrial complexes of this study were almost the same as that in each industrial complex and include fine dust, heavy metals, VOC, and PAH. However, because each complex is composed of various industrial plants, the major pollutants and pollution levels differ in each industrial complex; therefore, stratified analysis was additionally conducted to identify the effects on health of each industrial complex (Table S1). In the Pohang Industrial Complex, the prevalence of respiratory and allergic symptoms and asthma was high. Meanwhile, prevalence of allergic conjunctivitis was high in the Sihwa-Banwol Complex, while a high prevalence of acute bronchitis was noted in Gwangyang Bay Complex. Whether these results are related to exposure to specific hazardous substances in each industrial complex should be validated in future studies. In particular, health outcomes with a small number of symptoms should be evaluated using methods with statistical power.

A previous study conducted using the same data of this study did not identify any significant relationship between health outcomes and residency near the industrial complex [40]. This difference is due to differences in the categorization of health outcome variables and in the statistical analysis methods used. In a previous study, univariate analysis was conducted by dividing the disease diagnosis into three categories: "not treated," "treated," and "cured" [40]. However, in this study, multivariate analysis of the presence or absence of disease diagnosis was performed, and the effect of potential confounders was controlled. 
Therefore, the difference between the two results reflects the methodological difference, and not the actual difference.

This study has a few limitations. First, because lifetime symptoms and diagnosis are used as the outcome variables of the health effects, the temporality between exposure and health effects may be unclear. Moreover, the results of this study cannot be explained by causality because the data was collected from a cross-sectional study. Second, non-differential misclassification is possible as the exposed regions were classified in units of administrative regions (eup, myeon, dong levels) even though the level of exposure was not uniform in the same exposed regions due to the distance and wind influence. Third, although results of the stratified analysis of occupational exposure were not different, the industrial area group included a larger number of workers and the influence of occupational and environmental exposure cannot be divided clearly. Therefore, a longitudinal study is needed to clarify the relationship between the exposure to pollution from industrial complexes and health of residents in the surrounding area, and a scientific exposure assessment technique should be introduced to reduce the possibility of misclassification of the exposure. Despite the above limitations and regional heterogeneity between the complexes, this study is meaningful because it verifies the health effects from industrial complexes with high statistical power using pooled data from large-scale environmental epidemiology monitoring studies.

This study found that residents living in the vicinity of industrial complexes have a high risk of acute and chronic diseases including respiratory and allergic conditions. These results can be used as basic objective data for creating health management protocols for individuals residing in the vicinity of industrial complexes.

\section{ACKNOWLEDGEMENTS}

This study was supported by grant from the National Institute of Environmental Research in 2016, Republic of Korea (NIER-SP2016-295).

\section{CONFLICT OF INTEREST}

The authors have no conflicts of interest associated with the material presented in this paper.

\section{SUPPLEMENTARY MATERIALS}

Supplementary Material 1: Table S1 is available at https:// www.e-eht.org/.

\section{ORCID}

Sang-Yong Eom https://orcid.org/0000-0002-4559-8152

Jonghyuk Choi https://orcid.org/0000-0002-8661-493X

SanghyukBae https://orcid.org/0000-0002-4995-6543

Ji-Ae Lim https://orcid.org/0000-0003-0623-2446

Yangho Kim https://orcid.org/0000-0002-6462-0829

Hyun-Sul Lim https://orcid.org/0000-0001-9972-2561

Domyung Paek http://orcid.org/0000-0003-4510-6362

Heon Kim https://orcid.org/0000-0003-0329-5249

Mina Ha https://orcid.org/0000-0003-1011-9446

Ho-Jang Kwon https://orcid.org/0000-0003-3029-5674

\section{REFERENCES}

1. Loomis D, Grosse Y, Lauby-Secretan B, El Ghissassi F, Bouvard V, Benbrahim-Tallaa L, et al. The carcinogenicity of outdoor air pollution. Lancet Oncol 2013;14(13):1262-1263.

2. Burki TK. Twice as bad: new estimates for mortality from air pollution. Lancet Respir Med 2014;2(5):355.

3. Lelieveld J, Evans JS, Fnais M, Giannadaki D, Pozzer A. The contribution of outdoor air pollution sources to premature mortality on a global scale. Nature 2015;525(7569):367-371.

4. Pascal M, Pascal L, Bidondo ML, Cochet A, Sarter H, Stempfelet M, et al. A review of the epidemiological methods used to investigate the health impacts of air pollution around major industrial areas. J Environ Public Health 2013; 2013:737926.

5. Alwahaibi A, Zeka A. Respiratory and allergic health effects in a young population in proximity of a major industrial park in Oman. J Epidemiol Community Health 2016;70(2):174-180.

6. Tomášková H, Tomášek I, Šlachtová H, Polaufová P, Šplíchalová A, Michalík J, et al. PM10 air pollution and acute hospital admissions for cardiovascular and respiratory causes in Ostrava. Cent Eur J Public Health 2016;24 Suppl:S33-S39.

7. Riedl MA. The effect of air pollution on asthma and allergy. Curr Allergy Asthma Rep 2008;8(2):139-146.

8. Lee MR, Son BS, Park YR, Kim HM, Moon JY, Lee YJ, et al. The relationship between psychosocial stress and allergic disease among children and adolescents in Gwangyang Bay, Korea. J Prev Med Public Health 2012;45(6):374-380.

9. Jung SW, Lee K, Cho YS, Choi JH, Yang W, Kang TS, et al. Association by spatial interpolation between ozone levels and lung function of residents at an industrial complex in South Korea. Int J Environ Res Public Health 2016;13(7):728.

10. Hwang SH, Choi YH, Paik HJ, Wee WR, Kim MK, Kim DH. Potential importance of ozone in the association between outdoor air pollution and dry eye disease in South Korea. JAMA Ophthalmol 2016;134(5): 503-510.

11. Liu Y, Pleasants RA, Croft JB, Lugogo N, Ohar J, Heidari K, et al. Body mass index, respiratory conditions, asthma, and chronic obstructive pulmonary disease. Respir Med 2015;109(7):851-859.

12. Duan P, Hu C, Quan C, Yi X, Zhou W, Yuan M, et al. Body mass index and risk of lung cancer: systematic review and dose-response meta- 
analysis. Sci Rep 2015;5:16938.

13. Meader N, King K, Moe-Byrne T, Wright K, Graham H, Petticrew M, et al. A systematic review on the clustering and co-occurrence of multiple risk behaviours. BMC Public Health 2016;16:657.

14. Rajer M, Zwitter M, Rajer B. Pollution in the working place and social status: co-factors in lung cancer carcinogenesis. Lung Cancer 2014; 85(3):346-350.

15. van Eeden SF, Tan WC, Suwa T, Mukae H, Terashima T, Fuji T, et al. Cytokines involved in the systemic inflammatory response induced by exposure to particulate matter air pollutants (PM(10)). Am J Respir Crit Care Med 2001;164(5):826-830.

16. Farzan S. Cough and sputum production. In: Hall WD, Hurst JW, Walker HK, editors. Clinical methods: the history, physical, and laboratory examinations. 3rd ed. Boston: Butterworths; 1990, p. 207-210.

17. Zemp E, Elsasser S, Schindler C, Künzli N, Perruchoud AP, Domenighetti $\mathrm{G}$, et al. Long-term ambient air pollution and respiratory symptoms in adults (SAPALDIA study). Am J Respir Crit Care Med 1999;159(4 Pt 1):1257-1266.

18. Vedal S, Petkau J, White R, Blair J. Acute effects of ambient inhalable particles in asthmatic and nonasthmatic children. Am J Respir Crit Care Med 1998;157(4 Pt 1):1034-1043.

19. Yang CY, Wang JD, Chan CC, Chen PC, Huang JS, Cheng MF. Respiratory and irritant health effects of a population living in a petrochemical-polluted area in Taiwan. Environ Res 1997;74(2):145-149.

20. Kim YM, Kim J, Han Y, Jeon BH, Cheong HK, Ahn K. Short-term effects of weather and air pollution on atopic dermatitis symptoms in children: a panel study in Korea. PLoS One 2017;12(4):e0175229.

21. Kim J, Kim EH, Oh I, Jung K, Han Y, Cheong HK, et al. Symptoms of atopic dermatitis are influenced by outdoor air pollution. J Allergy Clin Immunol 2013;132(2):495-498.

22. Ahn K. The role of air pollutants in atopic dermatitis. J Allergy Clin Immunol 2014;134(5):993-999.

23. Um SB, Kim NH, Lee HK, Song JS, Kim HC. Spatial epidemiology of dry eye disease: findings from South Korea. Int J Health Geogr 2014; 13:31.

24. Torricelli AA, Novaes P, Matsuda M, Alves MR, Monteiro ML. Ocular surface adverse effects of ambient levels of air pollution. Arq Bras Oftalmol 2011;74(5):377-381.

25. Belli S, Benedetti M, Comba P, Lagravinese D, Martucci V, Martuzzi M, et al. Case-control study on cancer risk associated to residence in the neighbourhood of a petrochemical plant. Eur J Epidemiol 2004;19(1): 49-54.

26. Edwards R, Pless-Mulloli T, Howel D, Chadwick T, Bhopal R, Harrison $\mathrm{R}$, et al. Does living near heavy industry cause lung cancer in women? A case-control study using life grid interviews. Thorax 2006;61(12): 1076-1082.

27. López-Cima MF, García-Pérez J, Pérez-Gómez B, Aragonés N, López-
Abente G, Tardón A, et al. Lung cancer risk and pollution in an industrial region of Northern Spain: a hospital-based case-control study. Int J Health Geogr 2011;10:10.

28. García-Pérez J, Pollán M, Boldo E, Pérez-Gómez B, Aragonés N, Lope $\mathrm{V}$, et al. Mortality due to lung, laryngeal and bladder cancer in towns lying in the vicinity of combustion installations. Sci Total Environ 2009;407(8):2593-2602.

29. García-Pérez J, López-Abente G, Castelló A, González-Sánchez M, Fernández-Navarro P. Cancer mortality in towns in the vicinity of installations for the production of cement, lime, plaster, and magnesium oxide. Chemosphere 2015;128:103-110.

30. Fernández-Navarro P, García-Pérez J, Ramis R, Boldo E, López-Abente G. Industrial pollution and cancer in Spain: an important public health issue. Environ Res 2017;159: 555-563.

31. Brook RD. Cardiovascular effects of air pollution. Clin Sci (Lond) 2008;115(6):175-187.

32. Bartra J, Mullol J, Del Cuvillo A, Dávila I, Ferrer M, Jáuregui I, et al. Air pollution and allergens. J Investig Allergol Clin Immunol 2007; 17 Suppl 2:3-8.

33. Santibáñez-Andrade M, Quezada-Maldonado EM, Osornio-Vargas Á, Sánchez-Pérez Y, García-Cuellar CM. Air pollution and genomic instability: the role of particulate matter in lung carcinogenesis. Environ Pollut 2017;229: 412-422.

34. Mahalingaiah S, Hart JE, Laden F, Terry KL, Boynton-Jarrett R, Aschengrau A, et al. Air pollution and risk of uterine leiomyomata. Epidemiology 2014;25(5):682-688.

35. Umezawa M, Sakata C, Tanaka N, Tabata M, Takeda K, Ihara T, et al. Pathological study for the effects of in utero and postnatal exposure to diesel exhaust on a rat endometriosis model. J Toxicol Sci 2011;36(4): 493-498.

36. Hernandez AV, Pasupuleti V, Benites-Zapata VA, Thota P, Deshpande A, Perez-Lopez FR. Insulin resistance and endometrial cancer risk: a systematic review and meta-analysis. Eur J Cancer 2015;51(18):27472758.

37. Hopkins BD, Goncalves MD, Cantley LC. Obesity and cancer mechanisms: cancer metabolism. J Clin Oncol 2016;34(35):4277-4283.

38. Holmes D. Endocrine disruptors: air pollution linked to insulin resistance. Nat Rev Endocrinol 2016;12(12):688.

39. De Coster S, van Larebeke N. Endocrine-disrupting chemicals: associated disorders and mechanisms of action. J Environ Public Health 2012;2012:713696.

40. National Institute of Environment Research. Comprehensive evaluation on the result of four years (2012-2015) monitoring of exposure to environmental pollutants and health effects among residents living near industrial complex [cited 2017 Dec 29]. Available from http:// webbook.me.go.kr/DLi-File/NIER/06/023/5638949.pdf(Korean). 